\title{
THE PROPOSED INJECTION SYSTEM FOR AN ASYMMETRIC B FACTORY IN THE PEP TUNNEL
}

\author{
E. Bloom, F. Bulos, G. Loew, R. Miller, B. Sukjennicki, T. Martison* \\ Stanford Linear Accelerator Center \\ Stanford University, Stanford, CA 94309 \\ and \\ W. Barletta ${ }^{+}$ \\ Lawrence Livermore National Laboratory \\ Livermore. CA 94551
}

\section{ABSTRACT AND RNTRODUCTION}

The proposed asymmetric exergy B Faclory in be built in the PEP tunnel at SLAC oill require a highly effective and profuse snurce of low eminance electron and positron bunches The B Facton will consist of tao rings of equal size. a $9 \mathrm{Gel}$ electron rine and a 3 I GeV positron ring. each with 1658 bunches aith lotal circulating currents of 1.5 and 2.1 amperes respectuvely. As the lummosiny lifetime of the collider is expected to be about rovo hours. the mjector should be capable of filling the rings is a small fraction of an bour. II turns out that with some simple modifications. the SLC linac with its damping rings and positron source is ideally suited to fulcill this function effectively. The overall injection system is described belon.

\section{ע. SYSTEM SPECIFICATIONS AND DESCRIPTION}

The specifications and required parameters of the injection system are showin in Tabie $I$. II is seen that each of the 1658 siored bunches will require about $5 \times 10^{10}$ particles. In the Iopping-off filling mode $(80 \rightarrow 100 \%)$. assuming that each bucket receives aboul 5 single bunches from the injector with $50 \%$ filling efficiency. the linac will bave to provide single bunches of $4 \times 10^{9}$ paricles/bunch as compared to $2-5 \times 10^{10}$ particies/bunch in the regular SLC mode. This should be very easy In the full filling mode, the first $80 \%$ of each bucket will be filled. also with 5 linac bunches, but at the rate of $2 \times 1010$ particles/bunch. and the remaining $20 \%$ at the loppingoff rate as above. Assuming that bolb rings are filled by altemale linac pulses. each at a $\mathbf{6 0}$ pps rate, it is easily seen that the filling operations will take on the order of 3 and 6 minutes respectively:

A schematic of the SLC injection system is shown in Fig. 1. The injector will consist of the first 19 sectors of the linac. the two damping rings and the positron source. The $\mathbf{3 . 1}$ $\mathrm{GeV}$ positrous will be extracted at the end of Seclor 3 through a DC chicane which will let the electrons continue on, either to the end of Sector 7 for extraction at $9 \mathrm{GeV}$ via a slowly pulsed magnet, or to Sector 19 at about $30 \mathrm{GeV}$ for positron prnduction. The remaining II sectors of the linac may be

\footnotetext{
- K'ntk supporied by Department of Energy, contract DE-AC03-76SF. ousis

† Work wpponed by Department of Energy. contract W.7405-ENG 48
}

TABLE I

\section{FACTURY INJECTION SPFCLFICATIOAS ANI PARAMETERS}

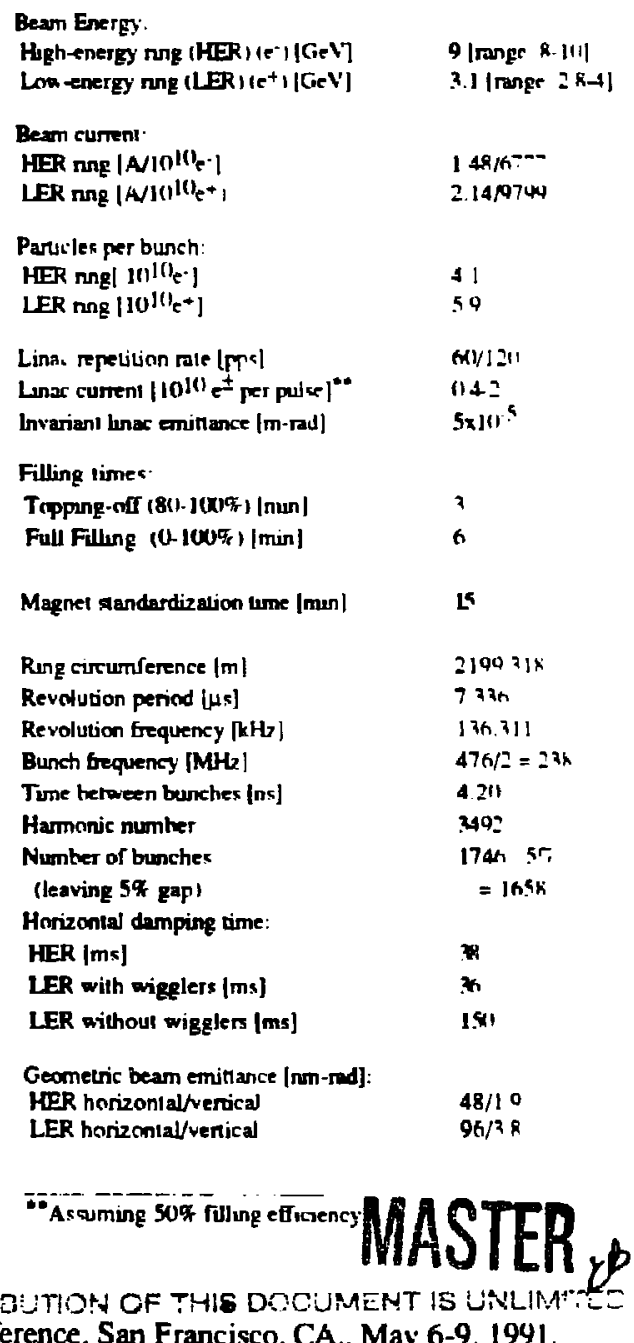




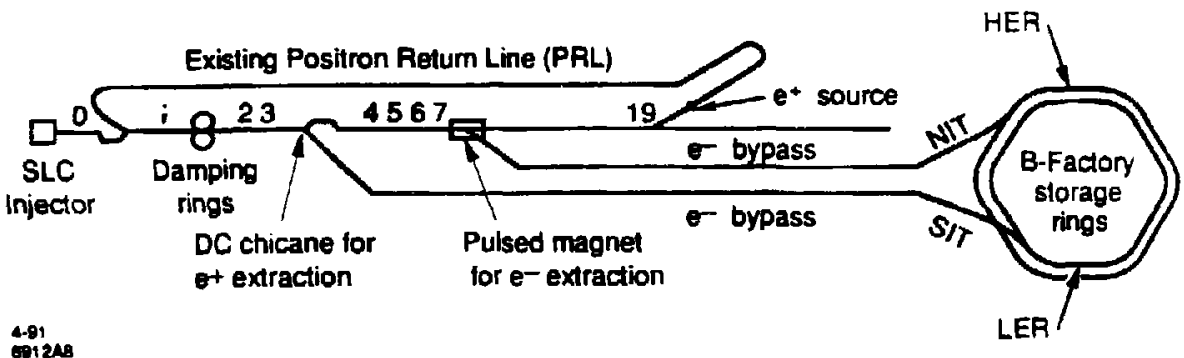

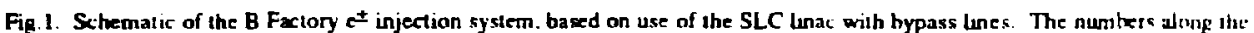
linac indicate the lecation (nm to seale) of each secior. Each of the $\mathbf{3 0}$ sectors is 100 ) $\mathrm{m}$ long

turned off. Oncre extracted, the respective bunches of electrons and positrons will be transminted through two separate bypass luocs to the exisuing NTT and SIT lines presendy used to fill PEP from the ead of the linac. The NIT and STT lines are well instrumented and will oot be described in this paper. The advantages of the system proposed here are numerous: a) it preserves al] other High Energy Physics opponunities at SLAC: b) the bunches leave the tinac at the desired eoergy. ubereby eliminating the Deed for backphasiog and minimizing rakefields in unnecessary accelerator siructures: c) by altemating $\mathrm{e}^{+}$and $\mathrm{e}^{-}$pulses at $60 \mathrm{pps}$. only one bunch will be stored at a time in each damping ring: d) no additional fast kickers (often unreliable) nill be needed: e) between filling times, it will be possible to "park" $e^{+}$and e- bunches at a low rale in NTT and SIT Faraday cups to optimize readiness for filling on demand: $n$ finally, by selecting a ring RF frequency of $476 \mathrm{MHz}$. i.e., $1 / 6$ of the linac RF frequency of $2856 \mathrm{MHz}$. synchronization will be greatly simplified.

The bypass lines will consist of $10 \mathrm{~cm}$-diameter aluminum pipe (for adequale pumping speed) witb 2.5 cm-diameter constrictions ever. $50 \mathrm{~m}$ where a FODO array of quadrupnles and beam position monitors sill be located. These apertures will be fully adequate since the low emittance beams will have or's of less than $1.5 \mathrm{~mm}$. A cross-section of the linac housing with the overhead-suspeoded quadrupoles

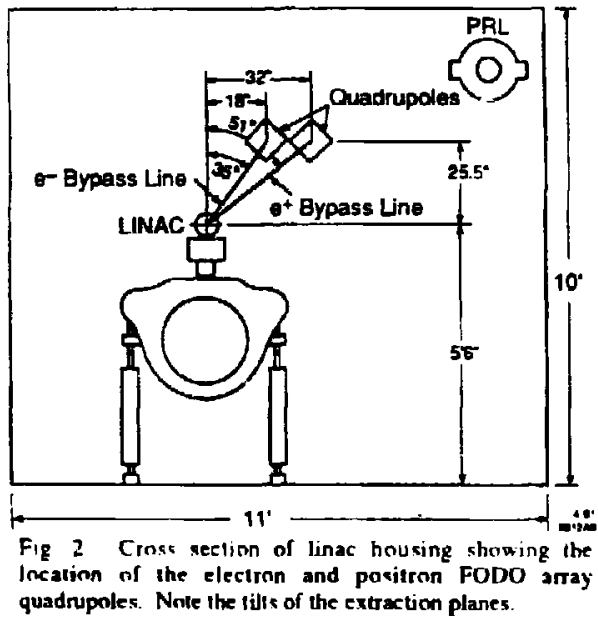

showing the respective tils of the extraction planes as given of Fig. 2. The existing posituon retum line (PRL is shnwn fir reference in the upper right-hand comet Table II gives a lis of the components in tbe bypass lines. The malching quadrupoles are par of 360 degree-phase advance arhrnmalli bends joining the linac to the bypass lides. and these in NIT and SIT

TABLE: II

LDVAC BYPASS L.INE CUMPUNENTS AVI" SPECIFICATIONS

\begin{tabular}{|c|c|c|}
\hline & POSITRON & EEL TRUN \\
\hline Length (t:m) & $-2 . h$ & -22 \\
\hline Energy (GeV) & 2.84 & 8.111 \\
\hline \multicolumn{3}{|l|}{ No. of quadrupoles: } \\
\hline Marching & 24 & 24 \\
\hline FODO arry & $\boldsymbol{I}$ & 4 \\
\hline Sieengig enneciors & (4) & 5 \\
\hline \multirow[t]{2}{*}{ Eeam positon montors } & 4 & sn \\
\hline & (tod readowst) & (sti readiuts) \\
\hline Prolite moninors & 2 & 2 \\
\hline Pumpe (120L/4) & 9 & $2 \pi$ \\
\hline $\begin{array}{l}\text { Vacuum roughung } \\
\text { connections }\end{array}$ & Z) & 2 \\
\hline Fatt valves & 1 & 1 \\
\hline Lolation valves & 14 & $1^{2}$ \\
\hline
\end{tabular}

\section{INJECTION INTO THE HER AND LER}

In contrast to the single PEP ring. for which the injection lines come down vertically into the plane of the ring and ar tangent to the inside. the HER and LER injection lires will to brought down on the outside of the two rings - intn the plane of the HER al IR-10 and into the plane of the LER a1 IR-8 The proposed method of injection is very similar to the onc used in PEP. 11 assumes $\beta_{2}=80 \mathrm{~m}$ and $\beta_{2}=20 \mathrm{~m}$ in $4(1)-\mathrm{m}$. long injection regions. Horizontal injection occurs as showin in Fig. 3. The closed orbil of the stored beam is lempurarily distorted by means of fous DC bump magnets and tbrec kickers. Details of the horizontal phase space $(3, x)$ for the stored and injected beam are shown at three scyucnial pounts in time following the tum-on of the DC bump magnets (1) stored beam is moved by $0.5 \mathrm{~cm}$ 10 DC bumped peistiun. $10 \sigma_{x}$ away from the inner edge of the $3-\mathrm{mm}$ septun. (II) stored bean is within $6 \sigma_{x}$ of the scplum mner edige incoming beam from the finac is langent to the slured-tean 


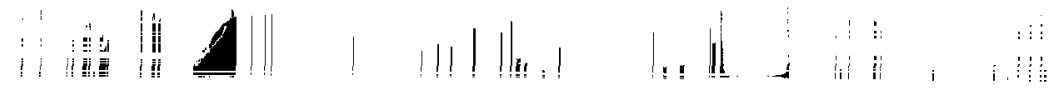

orhil and within $2 \sigma$, of the outer septum edge: (iii) approximately four hurs later, the stored beam is back to its DC lumped obut: the incoming bean is inside the ring within 20x of the inner septum edge. ready In damf ard merge with the slored beam. It is assumed that the injected beam bas a $\beta_{x}$ of $30 \mathrm{~m}$
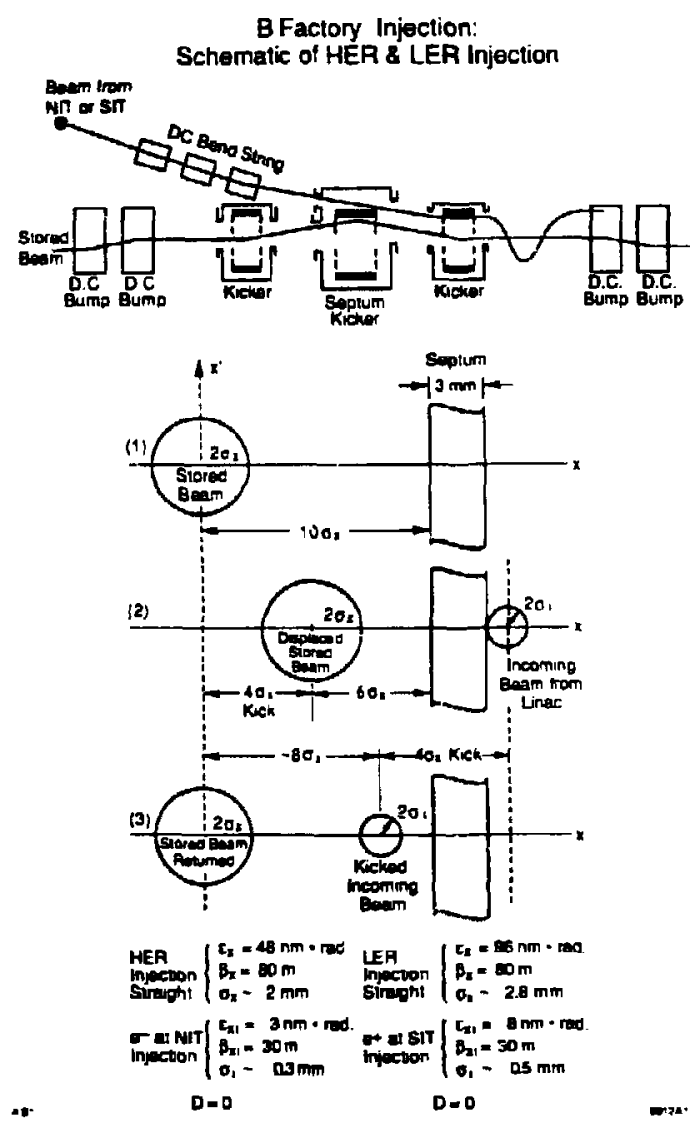

Fig. 3 Schemalic of Injection Kjcker System, and horizonial Imanverse phase space $\left(z, x^{\prime}\right)$ of stored and incoming beams during three xuccessive steps of the injection process (HER and LER). The diameters of the sored and incoming bearns are not drawn to acale.

For injection purposes. each ring is divided inlo nine rotating "zones" of equal length as shown in Fig. 4. A zone has a length of aboul $244 \mathrm{~m}$ (or $815 \mathrm{~ns}$ ) and costains 194 bunches. One of tbese zores in each ring will remain about hall empty to leave a gap for ion contol. We describe here the process for filling the LER at a $60 \mathrm{~Hz}$ rale: the HER is filled in a similar way. The transverse damping lime for the HER is
$38 \mathrm{~ms}$ and for the LER $36 \mathrm{~ms}$. If the damping contributon of the wigglers in the LER is ignored, a worsl-case situation in lems of injection, then the LER has a dampung time of 1.51] ms. The beginning of each zone is delermined by the time onsel of the kicker current pulses. All three kicker pulsess are identical. consisting of critically damped RLC circuits that nse and fall to practically zero within less than 1500 as The firs! bucket to be filled in $200 \mathrm{D}$ is located roughly $200 \mathrm{~ns}$ afier the beginuing of the kicker pulse so as to ride on the flat top where seusitivity to time jitter is minimized. Since the rise time of the pulse is much shorter than the fall time. bunches recenly stored in zone $\mathbf{n}-1$ are unaffected. Bunches in zone $\mathrm{n}+1$ (al keast $815 \mathrm{~ns}$ later) are kicked slightly. but since they have been in the ring for the longest time, their orbits are almost fully damped. and, to the extent bat the kickers are malched. these bumps are closed. Thus. single buckets in zones 1 through 9 are filled is succession, after which, 9 times I/60hb of a second, or $150 \mathrm{~ms}$ later (that is, one damping lime in the LER in (be absence of wigglers), the next adjacent buckets (4.2 ns laler) in each zone are filled, and sn $\mathrm{m}$. With this method, damping in the LER, even without wigglers. is adequate. The entire fulling sequence will be compules controlled and automated for both rings.
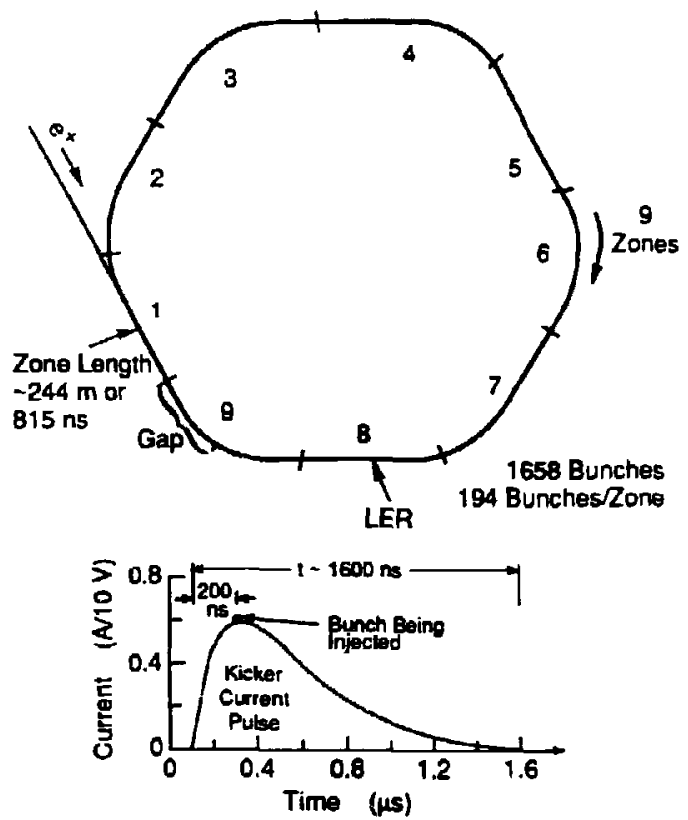

Zone Filling Sequence: $1,2,3,4,5,6,7,8,9$ (partially), 1.etc. . an

Fig. 4 Arimuthat zone filling sequence In the LEK. shnwing nine zones. The kicker pulse shown (ciyly filf all kickers) an computed by assuming charged. crituslly damped $R L C$ circuits $[R=2(L / C)] / 2]$ in abich the curreni reaches its maximum at $1=2 \mathrm{~L} / \mathrm{R}$ afier a thyratren is fired and allows the crruil to be discharged. 